This paper reports a study into
designing an information-measur-
ing system that could be used in
coal mines that are dangerous in
terms of the explosion of coal dust
and methane gas. The results of
reviewing technical advancements
in the field of fiber-optic system
development are given. To solve the
set task, prototypes of a fiber-optic
sensor of a new type and a hard-
ware-software complex were con-
structed. The research aims to
improve the safety of workers at
coal enterprises. The result of the
theoretical research has established
that additional losses related to a
micro bending should be taken into
consideration while accounting for
the effect of photoelasticity. The
fundamental difference between
the idea reported here and exist-
ing analogs is the development of a
hardware-software complex capa-
ble of working with a single-mode
optical fiber of great length with
a significant noise level. The data
processing unit is equipped with
a television matrix and can ana-
lyze changes in the pixels of a light
spot. The proposed system is qua-
si-distributed; it controls individ-
ual points within a rock massif.
The designed hardware-software
system provides high noise immu-
nity of measuring channels when
the external temperature changes.
The research results helped devel-
op an information-measuring sys-
tem for monitoring the deformation
and displacement of rock massif
layers based on fiber-optic sensors,
capable of operating in an explosive
environment. The system makes it
possible to control several layers
located in the roof of the workings,
while the fiber-optic sensor may
contain two or three sensitive ele-
ments that are connected to differ-
ent channels. With a sharp fluctu-
ation in pressure and an increase
in the displacement parameter, the
system triggers a warning signal
about the danger
Keywords: optical fiber, rock
displacement, roofing, mining work-
ings, fiber-optic sensors

UDC 620.179.18:681.586.3

DOI: $10.15587 / 1729-4061.2021 .244897$

\title{
DESIGN OF AN INFORMATION- MEASURING SYSTEM FOR MONITORING DEFORMATION AND DISPLACEMENT OF ROCK MASSIF LAYERS BASED ON FIBER-OPTIC SENSORS
}

\section{Vyacheslav Yugay} $\mathrm{PhD}$, Head of Department Department of «The technology of communication systems»*

Ali Mekhtiyev $\mathrm{PhD}$, Professor**

Yelena Neshina

Corresponding author

Master, Head of Department Department of Power Systems*

E-mail: 1_neg@mail.ru

BakhytkuI Aubakirova

Master, Senior Lecturer

Department of "Construction and Design"

M. Kozybaev North-Kazakhstan University Pushkin str., 86, Petropavlovsk, Republic of Kazakhstan, 150000

Raushan Aimagambetova

Master, Chief Specialist

Department of Strategic Development and Science Republic State Enterprise «Kazakhstan Institute of Standardization and Metrology» of the Committee of Technical Regulation and Metrology of the Ministry of Trade and Integration of the Republic of Kazakhstan Mangilik El ave., 11, Nur-Sultan, Republic of Kazakhstan, 010000

Aigul Kozhas

$\mathrm{PhD}$, Associate Professor

Department of "Transport and Logistics Systems"

Karaganda Buketov University

Universitetska str., 28, Karaganda, Republic of Kazakhstan, 100024

Aliya Alkina

Master, Senior Lecturer

Department of Information Technologies and Security* Madiyar Musagazhinov $\mathrm{PhD}$ Student**

Alexandr Kovtun

Master, Associate Professor

Department of Special Disciplines Military Engineering Institute of Radio Electronics and Communications Zhandossov str., 53, Almaty, Republic of Kazakhstan, A10M6C8

*Karaganda Technical University N. Nazarbaeva ave., 56, Karaganda, Republic of Kazakhstan, 100027 **Department of Electrical Equipment Operation

S. Seifullin Kazakh Agro Technical University

Zhenis ave., 62, Nur-Sultan, Republic of Kazakhstan, 010011
Received date 21.09.2021 Accepted date 11.11.2021 Published date 21.12.2021
How to Cite: Yugay, V., Mekhtiyev, A., Neshina, Y., Aubakirova, B., Aimagambetova, R., Kozhas, A., Alkina, A., Musagazhinov, M., Kovtun, A. (2021). Design of an information-measuring system for monitoring deformation and displacement of rock massif layers based on fiber-optic sensors. Eastern-European Journal of Enterprise Technologies, 6 (5 (114)), 12-27. doi: https://doi.org/10.15587/1729-4061.2021.244897

\section{Introduction}

The development of automated information-measuring systems (AIS) has followed a new direction with the advent of fiber-optic technologies. The direct purpose of optical fiber is the transmission of information in telecommunications, local computing systems, and automation. It is possible to highlight one more area of application of optical fiber (OF) related to measurements and monitoring. Based on fiber-optic technologies, various AISs, separate sensors, and monitoring systems 
have been designed. Fiber-optic sensors can monitor changes in electrical and non-eclectic quantities with high accuracy. Based on OF, it is possible to build any sensors capable of working even in explosive atmospheres. OFs are fireproof, since they transmit not an electrical signal but a light wave, which reduces energy costs for signal transmission. OF has low signal attenuation rates, practically not affected by various types of noise and destruction from a lightning strike. It should be noted that fiber-optic automated information-measuring systems (FAISs) have high noise immunity and low power loss in the measuring channels. At the same time, the length of the measuring channels can be tens of kilometers. The high bandwidth of OF and the speed of data transmission allowed it to completely displace communication cables with copper conductors in telecommunication systems. Fiber optic communication is uniquely suited for connecting data in real time.

OFs can be used as various sensors to monitor electrical and non-electrical quantities in various industries, aerospace, construction, oil and gas, and other industries. For example, OF can be used to control the deformation of metal and reinforced concrete structures of the support of coal mine workings during the displacement of rocks due to an increase in mountain pressure.

FAISs are of especial relevance for the mine workings of coal mines, dangerous in terms of the explosion of coal dust and methane gas. OFs allow them to be used as sensors and a guide system for data transmission in an explosive environment since no electric current is used for their operation. The data processing unit is to be located in the near-mine shaft yard or at the surface of the mine. FAISs do not use sources of ignition of the explosive atmosphere of the mine. Under such conditions, it is possible to use only special explosion-proof equipment with spark-safe circuits. The issue related to the need to design systems for measuring and monitoring the geotechnical state of mine workings, measuring the temperature of the layers, and the concentration of explosive gas is acute. Accordingly, it is necessary to build sensors and information processing devices whose hardware-software system would meet the safety requirements of coal mines. With timely reinforcement of the roofing, this issue can be avoided, but the lack of means to control the displacement of rocks that form the vault of the workings does not make it possible to avoid emergencies. It is also important that monitoring is enabled in real time.

\section{Literature review and problem statement}

Paper [1] reports the results of research into designing the AIS and fiber-optic sensor (FOS) based on a fiber Bragg grating capable of controlling water pressure. The disadvantage of that AIS is the significant cost of one measuring point, several times more than a mechanical reference station. The method is based on the use of an optical spectrum-analyzer, which is also expensive. The authors of [2] propose FAIS to control the pressure on the supporting and enclosing mine support of the workings. The disadvantage of the AISs reported in [1,2] is the use of a distributed fiber-optic sensor whose failure leaves the entire system out of operation, which is unacceptable for the safety requirements of coal mines. There is information about the development of a distributed fiber-optic system for measuring the deformation of rocks, capable of automatic monitoring of the geotechnical state of underground workings [3]. The system has similar problems associated with the breakage of the optical fiber of the distributed sensor, which were noted earlier for $[1,2]$. The above developments are not very effective since the enclosing and supporting roofing withstands a pressure of $40-50 \mathrm{MPa}$; they are equipped with pre-installed pressure gauges to control the load. So far, all the reported technical advancements are limited to laboratory samples or are at the stage of pilot tests. There are theoretical studies in the field of control of the stressed-strained state of rocks of mine workings [4], which also have not yet been implemented but may be interesting as a direction for the development of FAIS. There are several papers that address the design of intelligent FOSs [5], as well as their application under extreme conditions [6]. However, all the proposed ideas are still theoretical in nature and have not been implemented in practice. Analyzing the results of studies and the designs of laboratory samples, it is noted that their structure is quite complex and cannot be used to control the deformation of layers in coal mines. There is an experience in building FOS laboratory samples based on Bragg gratings that could replace outdated reference stations [7]; in addition, principles for using FOS to monitor the geotechnical state of mine workings in coal mines in China have been devised [8]. The use of Bragg gratings, in addition to the positive aspects, involves a complex enough FOS design, which leads to high cost. The structure of FOS is complicated due to the use of optical spectrum analyzers. These systems have disadvantages similar to [1,2]. This circumstance restrains the massive use of systems for monitoring the geotechnical state and other parameters of the workings of coal mines FOS based on the Bragg grating [9]. To design a new generation of AIS based on FOS, the issues related to FOS construction and operation were analyzed in [10]; the paper provides information on the need to combat interference arising in $\mathrm{OF}$ when its temperature changes. However, little attention is paid to the method of controlling additional losses, taking into consideration the effect of photoelasticity. The earliest work aimed to design FOSs based on Bragg gratings is [11]. The cited technical advancement was not introduced into production; the research ended with tests of laboratory samples. The safety of mining is an important aspect and priority in the operation of a complex mine system. Part of this problem can be solved by the introduction of AIS based on FOS to be built according to the Mach-Zehnder interferometer scheme [12]. The Mach-Zehnder fiber-optic interferometer for building long-base deform meters is suitable for use in open mines, its design is quite bulky and not suitable for use in ground-based conditions of coal mining. The authors note the problem of the presence of noise in the measuring channel when the temperature changes. There is evidence of research aimed at developing a fiber-optic interferometric receiver of seismic signals. However, the use of an interferometer is associated with a series of issues, first of all, with a change in the phase of propagation of the optical signal with a change in the temperature of the external environment [13]. There are papers where the physical and mathematical foundations of optics, as well as the principles of signal transmission in a fiber guide, are considered in detail. Variants of structure, technology, production, and design of special types of optical fibers for FOS were investigated in [14]. The cited paper provides general information about the main problems in the development of FOS. Several early works describing in detail the construction of FAIS based on FOSs were analyzed in [15]. The practical implementation of that method is associated with significant technical issues, as a result of which significant material investments would be required, which does not allow the introduction of AIS at mining enterprises. Research results aimed at simplifying the design of pressure sensors with microstructured optical fibers 
are presented in [16]. Important research has been carried out in the field of using FOSs based on Bragg gratings, reporting the results from their practical testing in the coal mines of China. However, the implementation is not yet expected since there are a series of unresolved technical challenges, and the cost of one measuring point is quite high [9]. This is the closest work to the topic of our paper although the use of Bragg gratings involves the use of expensive equipment, which would increase by several times the cost of one measuring point compared to existing reference stations. Accordingly, it is necessary to look for other methods to reduce the cost of FOS and AIS in general.

The fundamental difference between the idea and existing analogs is the development of a hardware-software system capable of working with a single-mode OF and analyzing the acquired data on changing the pixels of the light spot falling on the surface of the television matrix. The use of a single-mode OF makes it possible to significantly increase the distance from the place of FOS installation to the data processing unit. A single-mode OF has a stepped profile, it is described by the Gauss distribution; the light spot, in this case, contains a significant proportion of noise, especially when the temperature changes, which complicates the measurement process. Only the use of intelligent processing of the acquired data with the help of a specialized hardware-software system does resolve the above issues. The results of previous studies, a description of the principle of operation and construction of FAIS were set out earlier in [17], which reports the justification for the use of a quasi-distributed system as the most reliable one under the conditions of coal mines. The cost of a quasi-distributed system is lower relative to the distributed one, which is noted in [18]. The cited paper gives a description of the FOS and hardware-software system. The use of the optical fiber G-652 to control the rock massif of coal mines is considered in [19].

Our review of the literature has revealed that the deformation and displacement of layers are currently controlled with the help of mechanical reference stations, which are inspected by specialists of the surveying service at least once a day. The frequency of the inspection and the probability of error on the part of the responsible person do not ensure the completeness of the safety of mining operations. The review of the literature has demonstrated that the CIS countries have not yet introduced technical means capable of continuously monitoring the deformations and displacements of the rock massif layers during the day. The use of fiber-optic sensors ensures the explosion safety of AIS.

\section{The aim and objectives of the study}

The purpose of this study is to design an information-measuring system to monitor the deformation and displacement of rock massif layers based on fiber-optic sensors. This would enable a practical implementation in the form of a laboratory sample, which, in the future, could make it possible to scale it at mining enterprises.

To accomplish the aim, the following tasks have been set:

- to study theoretically the process of formation of additional losses at a micro bending, taking into consideration the effect of photoelasticity;

- to experimentally study the fiber-optic sensor of the deformation and displacement of rock massif layers;

- to design a measuring circuit of a quasi-distributed measurement system and the sensor's structure;
- to construct a prototype of the hardware-software system for a quasi-distributed system to measure the deformation and displacement of rock massif layers.

\section{The study materials and methods}

Based on the previous analysis, the idea came to our minds to design a system for monitoring the deformation and displacement of rock massif layers based on fiber-optic sensors that meet the requirements for coal mines. To practically verify the hypothesis and the results from theoretical studies, a laboratory sample of a fiber-optic sensor and FAIS with 4 active channels were designed, which would suffice to conduct experiments. For the study, we constructed a model of a mine working with an arched support, which makes it possible to conduct full-scale experiments and simulate the impact on fiber-optic sensors. This would make it possible to build an operating FAIS model to be subsequently implemented at actual mining enterprises.

The base of the research method is the known effect of photoelasticity for the case of a micro bending, and the method for measuring additional losses arising in the optical fiber exposed to mechanical action. Combining these methods could make it possible to design a FOS that operates on a completely different principle. The FAIS would be built according to the known quasi-distributed type since individual points within a rock massif are to be controlled. Underlying the FOS is a wellknown structure of the mechanical station of visual control, which has no return action. A given device is well established, is easy to use, not expensive, at about USD 80. Despite all the advantages, the device does not make it possible to automate the control process and is an outdated product of the last century. The FOS proposed has a similar mechanical part, similar in principle to the reference station, which makes it possible not to exceed its cost above USD 100; this is one of the advantages for implementation. When designing FOS, it was decided to abandon the use of optical interferometry methods due to the need to employ three OFs, two measuring ones and one returning. An optical interferometer, the type of Mach-Zehnder, has many drawbacks that limit its use in mine conditions and primarily depends on the temperature of the OF. This circumstance, given a significant length of the measuring channel of several kilometers, could lead to critical errors. In measurements with a temperature fluctuation of even less than $1{ }^{\circ} \mathrm{C}$, the refractive index may change with the operation of the measuring system in general disrupted. Also, when designing FOS, no known methods of optical interferometry, Bragg fiber gratings, longflow fiber lattices were used. Even though using these methods makes it possible to build a distributed FAIS with one OF per measuring channel several kilometers long, challenges remain. The issues are the same as those related to interferometers but the cost of one measuring point would increase significantly.

Having analyzed the situation, it was decided to design FOS using the quartz single-mode optical fiber Corning SMF-28e(STANDARD ITU-T G.652.D) with a diameter of $9 / 125 \mu \mathrm{m}$, which is used for the manufacture of telecommunication cables. This would reduce the cost of FAIS in general and make it possible to use a standard armored fiber-optic cable, which is widely used in telecommunication systems, as a guide communication system with sensors. The cable is multi-fiber and gel-filled with up to 120 cores. Each FOS uses two conductors, one in a straight direction when the light 
propagates from the source to the sensor, and one reverse when the light returns from the sensor to the television matrix and data processing unit. One cable could make it possible to form 60 measuring channels with the same number of sensors. At present, the laboratory sample has 4 active channels, which is enough to conduct experiments but the program makes it possible to increase their number. FOS is enabled by optical convectors and adapters of SC or FC type since welding work in the conditions of the explosive environment of the mine is prohibited. The maximum loss of optical power reaches $0.2 \mathrm{~dB}$, which is several times higher compared to welded joints. With the length of the measuring channels of several kilometers, this is not critical since the light wave would be powerful enough for the perception by the television matrix.

Fig. 1 shows a simplified structural diagram explaining the essence of FOS operation. As a radiation source, a coherent semiconductor laser 1 operating in pulsed mode is used. As a sensitive sensor 2, we use a single-mode optical fiber with a core and shell size of $9 / 125 \mu \mathrm{m}$. At the site of mechanical action 3, a micro bending is formed, while the loss of optical power of the light wave propagating along the $\mathrm{OF}$ increases. At the output from the fiber, beam 4 is formed, falling on the sensing surface of the photosensing television matrix 5 , on the surface of which a light spot is formed. Next, the light waves are converted into an electrical signal and enter the signal processing device 6 , which is connected to the personal computer 7. With mechanical action on the optical fiber, the effect of photoelasticity occurs, and the refractive index between the shell and the core changes. That leads to a change in the properties of light and an increase in the additional losses introduced, namely the phase of the mode of the light wave and its intensity. All changes in the light spot are recorded by a television matrix and transmitted through the converter to the signal processing device.

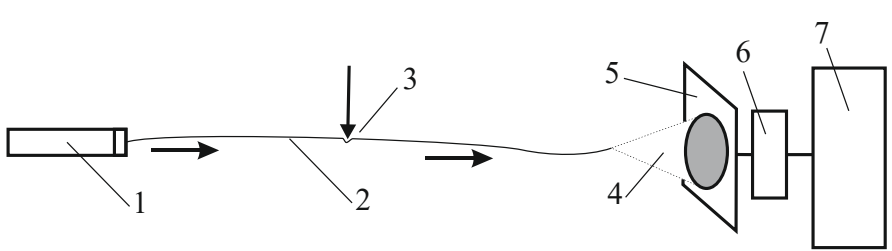

Fig. 1. Simplified structural diagram

A significant problem for the presented scheme is that the single-mode fiber is quite sensitive to temperature effects. A change in the ambient temperature of $0.5^{\circ} \mathrm{C}$ causes a change in the phase of propagation of the light wave inside the OF, which leads to interference and distortion of the measurement data obtained. An important point is the method used to combat temperature interference and noise, which makes it possible to determinize random fluctuations, as well as dynamically change the initial settings of "zero" when noise increases. It is necessary to consider the profile of the optical beam output from the OF (Fig. 2). The numerical aperture for the input of the beam from the light source can be represented by the following expression:

$$
N A=\sin Q=\left(n_{2}^{2}-n_{1}^{2}\right)^{0.5}=1 / p W_{0} .
$$

We take the value $N A=0.17$, and $Q=9.8^{\circ}$.

Since the OF shell is made of glass with a reduced density, and its core is made of glass with increased density, the refractive indexes must meet the conditions $n_{1}<n_{2}$, and the angles of incidence and refraction would equal $\alpha_{i n}=\alpha_{\text {out }}$. At the same time, the refractive indexes $n_{1}=1.4570$ and $n_{2}=1.4625$. The OF works with full inner reflection of the light beam, which propagates along its core, without going beyond the interface of the two media.

Power loss

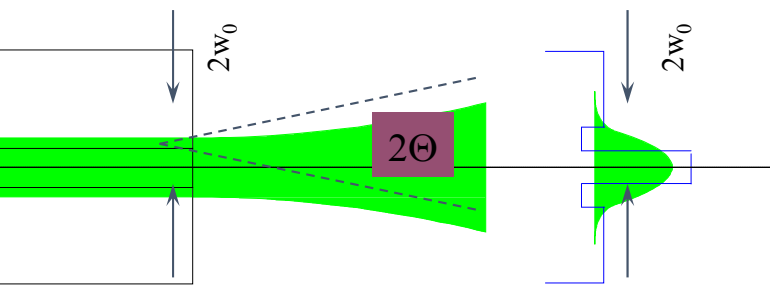

Permissible angle

spot at the outlet of OF and spectral characteristics of the radiation source

Fig. 3 shows an image of a light spot incident to the surface of the television matrix.

A profile was formed that obeyed the Gaussian law of distribution. The light spot itself, falling on the surface of the television matrix, contains a lot of noise, so the transition to a single-mode fiber is associated with significant difficulties.

We can also say that the light spot itself is not informative and is the noise of a light wave passing through the core of a single-mode fiber. For the construction of distributed FAISs, this method of light spot analysis is not suitable but it is quite acceptable for a quasi-distributed FAIS. Using computer analysis of the results of the transition of pixels from black to white, one can calculate their number and obtain a numerical value of the mechanical impact. The greater the amount of pressure on the $\mathrm{OF}$, the more white pixels are formed in the light spot analyzed by the program.

Individual bursts, which are interference, are determined by the hardware-software system to exclude false alarms. Machine learning capabilities are used to control the shape of the light spot, which allows the system to be adapted to any conditions of the mining enterprise. The system can control the change in mining pressure and displacement of the roof rocks by changing the level of additional losses, changing the intensity of the light wave falling on the surface of the photodetector. At the same time, intelligent processing of the spot image makes it possible to track the change in the intensity of individual pixels. The hardware-software system can track the rate of change in the derivative of the intensity of the light wave in time. The system can also change its sensitivity in stages; initially, it is set to maximum sensitivity to control initial displacements and give warning signals to the operator. After that, the parameters are automatically coarsened for the accuracy of fixing the displacement and excluding false measurements. 


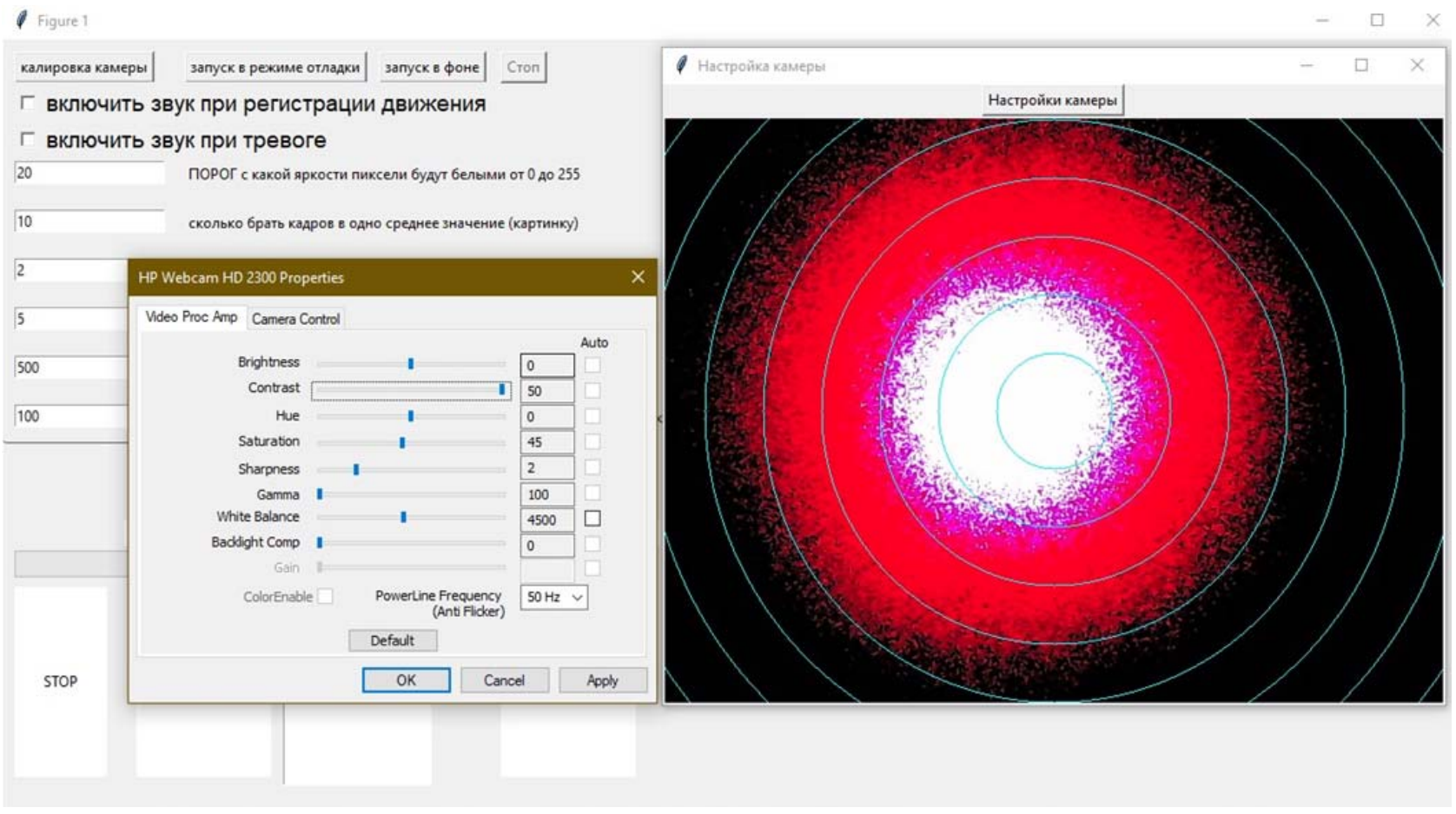

Fig. 3. Image of a light spot incident to the surface of a television matrix

As a sensing element for FOS, we used a single-mode optical fiber, G652 standard, 125/9 $\mu \mathrm{m}$, and a diameter of a protective shell of $0.9 \mathrm{~mm}$. For connection, we used adapters UPP $2.5 \mathrm{~mm}$ and optical connectors, the type of SC. Calibration of the laboratory sample was performed using the VIAVI optical power meter (JDSU) SmartPocket OLP-38 (USA); the optical radiation source used was SmartPocket OLS-34/35/36 (USA). These devices are used to control the parameters of additional losses of fiber-optic transmission lines. An electronic dynamometer was used to measure the mechanical load. Boundary conditions: the pressure on the fiber is from 0 to $50 \mathrm{~N}$. The displacement was measured using a ruler. The temperature in the laboratory room ranged from 23 to $25^{\circ} \mathrm{C}$. As a result of automated data fitting, single-factor mathematical models were built. Each measurement was carried out 10 times. The boundary conditions for the application of force on the OF are from 0 to $50 \mathrm{~N}$.

To process the experimental data, we used the tools of the Microsoft Excel tabular processor (USA), quadratic interpolation of the function (solid line), and the results of RMS approximation (dotted line); regression analysis was also performed. The adequacy of the obtained approximations was checked using the software tools Microsoft Excel (USA) and Wolframalpha (USA).

The numerical study was conducted using the Wolframalpha program (USA), which is an interactive system for treating experimental results; it is focused on working with data arrays. The Akaike Information Criterion (AIC), used exclusively for selection from several statistical models, was taken into consideration. With the help of the program, absolute and relative errors were calculated, and the Student's coefficient was determined at a confidence interval of 0.95 .

\section{Results of studying the information-measuring} control system

5.1. Results of the theoretical studies of the process of formation of additional losses at a micro bending, taking into consideration the effect of photoelasticity

In the normal state, light travels along the core of the OF for a considerable distance due to the known reflection effect but, when a micro bending occurs, shown in Fig. 4 by an arrow, there is a change in the phase of propagation of the light wave. The change in the properties of light propagating through the core of the optical fiber occurs as a result of the effect of photoelasticity since the bending of the OF leads to a slight change in the refractive index $\Delta \mathrm{n}$ between the core and the shell of the OF. On this basis, various FOSs work, including those built on the basis of interferometers. In comparison with information-measuring systems, which are based on optical interferometer or reflectometer, the proposed system has a fundamentally different physical basis for functioning.

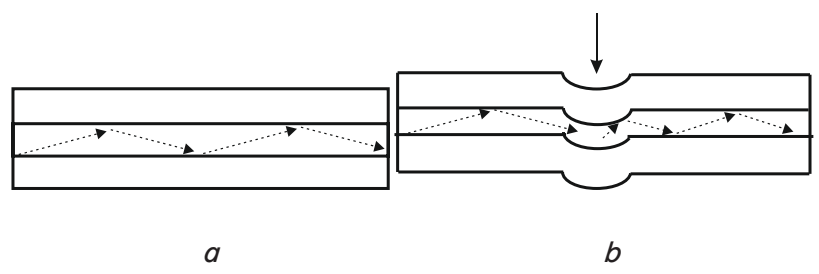

Fig. 4. Changing the properties of light passing through the optical fiber under external mechanical action on it:

$a$-before mechanical action; $b$ - after mechanical action

For example, when using a Mach-Zehnder optical interferometer, it is necessary that the light wave from the co- 
herent source be separated and sent along two OFs towards the photodetector. At the same time, in one of the fibers, a displacement of the propagation phase of the light wave $\Delta \phi \sim \Delta \mathrm{n}$ is formed. The two beams are then combined into one interference spot, which is an alternation of light and dark areas. If even a slight OF micro bending occurs, the interferometer's pattern could change and there would be a displacement of the light areas inside the spot. The change in the propagating phase of the light wave $\Delta \phi \sim \Delta$ n plus the change in the vector of the electromagnetic field of wave $E$, affect the polarization of the radiation. Such FOS has a significant sensitivity and can register displacements within a few $\mu \mathrm{m}$. Accordingly, two OFs in the forward direction and one in the opposite direction are needed to return the light wave to the data processing unit, since it contains a photodetector.

There is no interference light spot since the FOS is connected only by one OF. As shown earlier in Fig. 3, at the output of the OF, a stepped profile of the light spot is formed; it contains a significant amount of noise, which adversely affects the FAIS operation. Since constant changes in the phase of propagation of the light wave lead to interference and the formation of false readings of the measured value, the coherence of the radiation source is important. Accordingly, one cannot do without a dynamic noise reduction system for the arising interference. The Mach-Zehnder interferometer has several drawbacks, for example, the dependence of the phase of propagation of a light wave on temperature. Given this, when the temperature changes within $1{ }^{\circ} \mathrm{C}$ or more, it can lead to the system freeze and a false alarm, while there was no mechanical effect on the sensor.

The photoelastic effect causes a change in the properties of light, namely its intensity $I(t)$. The source must necessarily be coherent since a change in frequency would disrupt FAIS operation. Coherence is one of the parameters for any FAISs. All changes in intensity are recorded by the photodetector. Intensity is associated with tension $I \sim \overrightarrow{E^{2}}$. Based on the well-known theory explaining the work of the optical interferometer, the vectors of intensity of coherent waves falling on the surface of the photodetector can be represented by the following expression:

$$
\begin{aligned}
& E_{1}=E_{01} \cos (\omega) t-\varphi_{1}, \\
& E_{2}=E_{02} \cos (\omega) t-\varphi_{2} .
\end{aligned}
$$

When the waves are complied, the total vector $E=E_{0} \cos (\omega t-\varphi)$ is obtained.

At the same time, the phase difference $\Delta \phi=\Delta \phi_{H}+\Delta \phi(t)$ where is the initial phase difference of interfering light waves; $\Delta \phi_{H}(t)$ is a phase difference associated with a change in the conditions of light propagation in an optical fiber under external mechanical influence.

When the temperature changes, there is a change in $\Delta \phi_{H}$, which causes a malfunction of FAIS and a false alarm, while there was no mechanical effect on the sensor. The phase difference of light waves $\Delta \phi_{H}$ is random and requires constant adjustment, and the change in its parameters is a significant problem in the efficiency of the entire system under actual conditions.

The surface of the television matrix receives not the sum of two waves but only one, and not the change in the light spot is controlled but the transition of pixels from white to black. This reduces the negative impact of temperature changes on FAIS operation. Simplification of the principle of operation makes it possible to reduce the cost and increase the noise immunity of FAIS during temperature fluctuations in the external environment surrounding the OF. The second difference is the transition from a distributed scheme of FOS location to a quasi-distributed one. This resolves a series of significant problems inherent in the FAISs built on the basis of an interferometer, reflectometer, or Bragg gratings.

Temperature correction reduces the impact of interference and pulse repetition delays in self-oscillation mode. Theoretical studies have shown that depending on the magnitude of the mechanical impact on the OF, there is a micro bending. That leads to the appearance of additional or so-called introduced losses while reducing the intensity $I$ of the light wave falling on the surface of the television matrix, as well as changing the refractive indexes $\Delta n$ in the OF. Also, the refractive index changes with a change in temperature.

$$
\frac{\Delta I}{I}=\frac{1}{I\left(\frac{d I}{q T}\right) k \Delta T}+\frac{\delta I}{I},
$$

where $I$ is the intensity of radiation at the output from the optical fiber;

$\Delta l$ is a change in intensity;

$\left(\frac{d I}{q T}\right) k$ is the private derivative of the temperature dependence of intensity;

$\delta l$ is the change in intensity due to photoelasticity;

The dependence of the refractive index of the core on temperature and deformations can be expressed by the following formula:

$$
\frac{\Delta n}{n}=\frac{1}{n}\left(\frac{d n}{d T}\right) p \Delta T+\frac{\delta n}{n},
$$

where $n$ is the refractive index of the core of the optical fiber; $\Delta n$ is a change in the refractive index;

$\left(\frac{d n}{d T}\right) p$ is the partial temperature derivative characterizing the change in the density of quartz glass; ticity.

$\delta n$ is a change in the refractive index due to photoelas-

For example, if the length of the distributed FOS is $1 \mathrm{~km}$, then its deformation would be approximately $0.3 \%$, while there are changes in the signal delay. With an increase in the length of the distributed FOS to $5 \mathrm{~km}$, and with a maximum pulse period in the self-oscillation mode, it would be about $50 \mu \mathrm{s}$. The number of accumulated pulses, recorded by the photodetector, would equal 38 , for the accumulation time of no more than 30 seconds. Accordingly, there is a change in the accumulated pulses depending on the length of the measuring channel and its deformation with changes in temperature. It is possible to carry out temperature adjustment of the measuring channel. If the temperature relative to the original value changes by $5{ }^{\circ} \mathrm{C}$, the $\Delta n$ value is $4,964 \cdot 10$. With a distributed FOS length of $5 \mathrm{~km}$ and an accumulation time of 30 seconds, the delay would be within $0.16 \mathrm{~ns}$, then the number of accumulated pulses would equal 28 , which is different from the original FAIS calibration. If the length of the distributed FOS increases to $10 \mathrm{~km}$, the difference would be even more significant. The use of a quasi-distributed FAIS could avoid these problems, and significantly at that, since the sensing element is small enough and has a length of only a few centimeters. 
5. 2. Results of the experimental studies of a fiber-optic sensor of deformation and displacement of rock massif layers

Fig. 5 shows a scheme of our experiment. The software used for data processing is installed on computer 1 . The radiation source with a $650 \mathrm{~nm}$ wavelength and a power of $10 \mathrm{~mW}$ is located in the data preprocessing unit 2, to which it is connected using an optical connector 3 , a single-mode patch cord 4. FOS consists of a movable disc 5, an elastic damper 6 , and a fixed disc 7 . The sensing element 8 is made of a single-mode OF, the G652 standard, $125 / 9 \mu \mathrm{m}$, and is located on damper 6 between the movable 5 and fixed 7 discs. The lightwave, passing through sensing element 8 , returns to the data preprocessing unit 2 and falls on the surface of the television matrix. Unit 2 also hosts a microprocessor for data pre-processing. One television matrix is installed on each measuring channel. The movable disc 5 is connected to stud 9, which can move in the directions indicated by the arrows. The stud is connected by ring 10 to the tension coupling 11. In the experiments, two tension couplings were used to make it more accurate to displace disk 5 and form pressure through it on the sensor element 8 . When tightening the tension coupling, the pressure on the sensing element 8 increases; with the weakening of the tightening, it, on the contrary, decreases. To measure the applied force, dynamometer 12 is used. The end of the second tension coupling is fixed on a fixed support 13, which ensures the tension of the entire structure and the loading of the sensing element. Computer screen 1 displayed the windows of the program for processing measurement data. Experiments were conducted indoors at a temperature of $22{ }^{\circ} \mathrm{C}$.

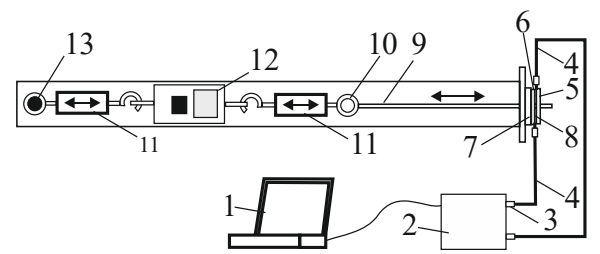

Fig. 5. Scheme of the experiment: 1 - computer light source,

2 - data preprocessing unit, 3 - optical connector,

4 - single-mode patch cord for sensor connection,

5 - movable disk, 6 - damper, 7 - fixed disk, 8 - sensing element tension coupling, 9 - stud, 10 - connecting ring, 11 - tension coupling, 12 - load meter, 13 - fixed support

The results of the sensor study are shown in Fig. 6 .

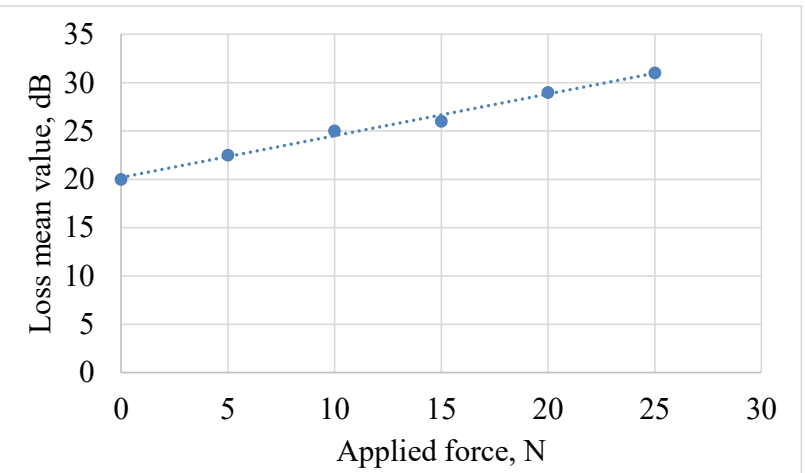

Fig. 6. Plot of the dependence of optical losses on the applied force
Experiments were carried out to determine additional power losses of optical radiation passing through a fiber-optic sensor with different applied force. The measurements were carried out repeatedly with the subsequent processing of the experimental data and averaging the obtained values. The results of our experiments were processed taking into consideration the lowest value of the Akaike information criterion.

During the automatic fitting, the following results were obtained:

1. $0.431429 \mathrm{P}+20.1905=\mathrm{A}$ linear approximation;

2. $-0.000357143 \mathrm{P}^{2}+0.440357 \mathrm{P}+20.1607=\mathrm{A}$ second-power approximation;

3. $0.000407407 \mathrm{P}^{3}-0.0156349 \mathrm{P}^{2}+0.579894 \mathrm{P}+20.0079=\mathrm{A}$ approximation of the third power (cubic).

The best-fit mathematical model in terms of AIC (Akaike Information Criterion) is the linear approximation. As a result, a laboratory prototype of the fiber-optic sensor demonstrated fairly high linearity. According to the measurement results, an absolute error of 2.27 , a relative error of $8.844 \%$, and a Student coefficient of 2.120 with a confidence interval of 0.94 were calculated.

5. 3. Results of designing the scheme of a quasi-distributed measurement system and the structure of the sensor

The emergency condition of the roofing support requires measures to eliminate it, respectively, it is required to strengthen the structure with additional elements that enhance its rigidity. Excessive margin of safety leads to additional costs. Fig. 7 shows a photograph of the deformation of the elements of the mine support caused by the displacement of rock massif layers of the vault of the working.

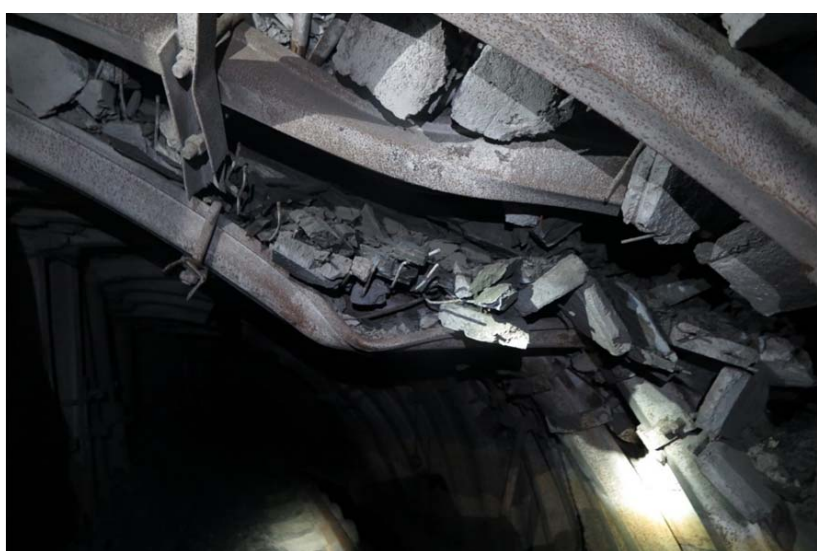

Fig. 7. Photograph of deformation of the elements of the mine support caused by the displacement of rock massif layers of the vault of the working

FAIS is based on a quasi-distributed measuring circuit; each sensor is, accordingly, connected to a separate television matrix to control changes in the parameters of the light spot. The radiation source must be necessarily coherent since all frequency fluctuations lead to the occurrence of various kinds of interference. The laser beam is divided into the required number of channels using an optical splitter. FAIS is designed to measure the parameters of the displacement of the layers of the roof of the mine workings with a change in pressure, in an explosive environment. The experience of operation of mechanical reference stations has shown that the 
displacement of rocks occurs when the mountain pressure changes and directly depends on the change in its value. The change in the mining pressure on the production support occurs due to the advancement of the treatment face and the excavation of coal, after which there is a void. In the formed cavities, the rock of the roof collapses, since the enclosing protective support moves along with the combine machine and no longer supports the vault of the working. The rock is sagged and the working space is squeezed by the rocks. FOSs are installed in the area of cleaning in the recouping tracks, which transport the extracted coal, move equipment, cargo, and people. Approximately about 200-300 meters from the face, zones of high pressure are formed, which create increased pressure on the support. When the mining pressure changes in certain areas adjacent to the treatment face of the workings, the support is deformed or partially destroyed. It is important to know exactly the place where displacements occur and the mountain pressure of the layers changes, which would make it possible to strengthen the support in a timely manner and prevent the collapse of the working. FOS has a structure similar to a mechanical reference station as this measuring device is simple and reliable, and has also proven effective as a means of warning about the displacement of rocks. Its main drawback is the impossibility of automatic control and one-time action since there is no possibility of returning to the original state.

Fig. 8 shows photographs of the equipment used, as well as the design of the tension mechanism.

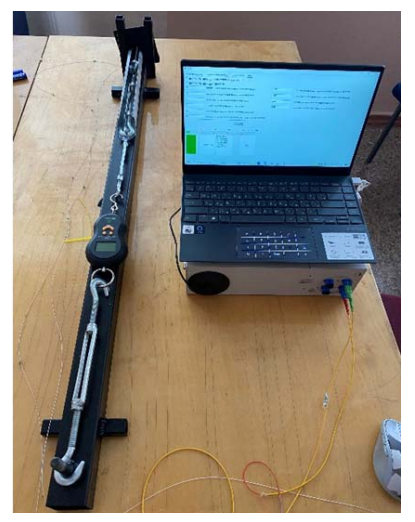

$a$

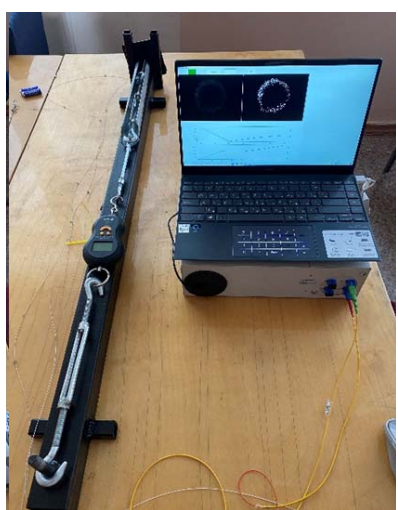

$b$
Fig. 8. Photograph of the equipment used: $a-$ window of the hardware-software system; $b$ - window of the program "Run in debug mode"

FOS is placed in a pre-drilled hole in the roof of the workings with a step of 30-50 meters, depending on the geotechnical state of the working. The process of installing FOSs and reference stations is almost identical, which would not cause the need to replace drilling equipment. Approximately 30 sensors are needed to control the two haulage drifts. The control area can be expanded, if necessary, to one kilometer, and the number of installed FOSs can be increased to 120 per measuring unit. One measuring channel accounts for two OFs, respectively; along one OF, a beam of light comes to the FOS, and, along another, moves from it to the television matrix located in the data processing unit. FOS is connected to the measurement data processing unit through a fiber-optic cable. When using a laser with a $650 \mathrm{~nm}$ wave, the distance is about $20 \mathrm{~km}$ with a radiation power of $30 \mathrm{~mW}$;

when switching to the range of $850-1550 \mathrm{~nm}$, it is possible to increase the distance to $50 \mathrm{~km}$. This is quite enough for long workings at any mine. An important point of the industrial introduction of FAIS is the cost of one measuring point, which is about USD 90, and, at serial production, a significant reduction in the cost of one sensor is possible. The difference in the cost between mechanical reference stations and FOS is about USD 20-30, which is not significant since the cost of eliminating roof support accidents and blockages is much more expensive. Reference stations are periodically monitored by a person and it is not always possible to establish all changes in mountain pressure. The presence of the human factor and the need to attract specialists of the surveyor service only to control reference stations does not meet modern production requirements and does not ensure the development of digitalization of the coal mining process. All FOS connections are made with the help of standard universal adapters UPP $2.5 \mathrm{~mm}$ and optical connectors of the SC or FC types, which guarantees complete explosion safety during installation work. Fig. 9 shows a measuring diagram of a quasi-distributed FAIS and demonstrates the FOSs installed in the boreholes drilled in the roof of the mine workings.

67

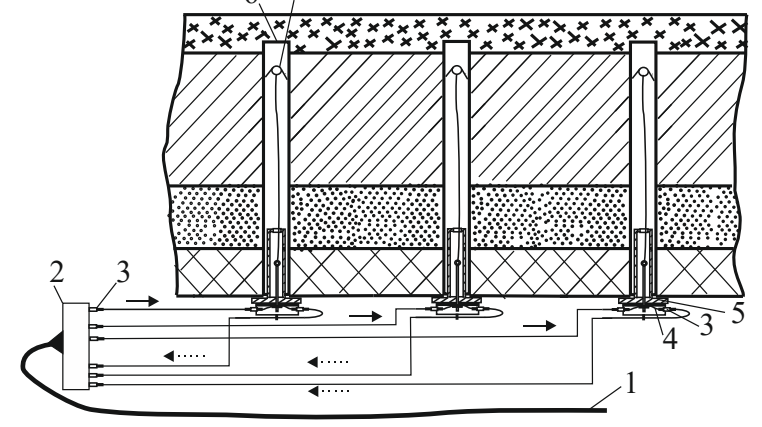

Fig. 9. Diagram of a quasi-distributed measurement system with fiber-optic sensors: 1 - armored fiber-optic cable, 2 - optical cross, 3 - optical patch cords of measuring channels of forward and reverse direction of movement of light waves, 4 - sensing element, 5 - body of FOS with a guide system, 6 - borehole, 7 - spring retainer

Fiber-optic cable 1 is used to send a light wave from the radiation source. The cable is connected to the optical cross 2 , to which sensitive element 4 , which is the measuring part of the FOS, is connected with the help of optical patch cords 3 with convectors. As a guide system, an armored fiber-optic cable 1 is used, as this is required by safety rules. The sensing element 4 is fixed on body 5 , which has a guide element for centering in the hole of the borehole 6 . As an element that registers displacements, a spring retainer 7 is used, which comes into motion when the layers are displaced and, through a flexible connection, acts on element 4. Arrows show the direction of movement of light in the forward and reverse direction.

Fig. 10 shows the structure of FOS, which was designed on the basis of a laboratory prototype. The FOS structure has much in common with a standard reference station but the fundamental difference is the use of a single-mode fiber as a sensing element. FOS is connected using fiber-optic patch cord 1, through which a beam of light comes to the sensor. 


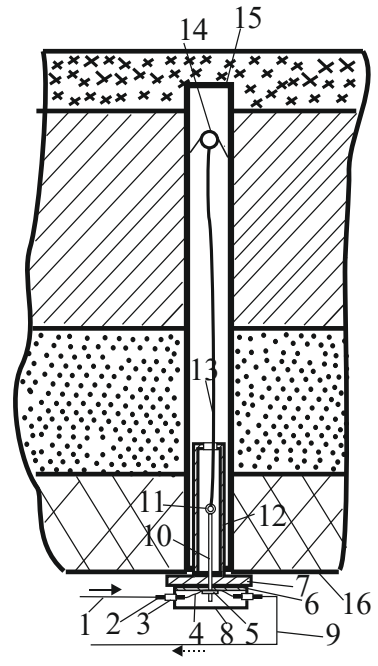

Fig. 10. Displacement sensor design for fiber-optic quasidistributed monitoring system: 1 - optical patch cord of direct beam direction, 2 - optical connector, 3 - adapter, 4 - sensing element, 5 - movable disk, 6 - damper, 7 - fixed disk, 8 - protective cover, 9 - optical patch cord of the reverse direction of the beam, 10 - stud, 11 - hole, 12 - guide system, 13 - cable, 14 - spring retainer, 15 - borehole, 16 - roof of mining

On both sides of patch cord 1, there are optical connectors 2 . Connectors are connected to adapter 3 , which provides the possibility of connecting FOS during its installation. The sensing element 4 is pressed by a movable disc 5 . The sensing element 4 is located on a soft damper 6 between the movable disc 5 and the fixed disc 7 . To mount adapters 3 , a protective cover 8 is used, which ensures tightness and prevents the penetration of coal dust inside. Along the optical patch cord 9, a beam returns to the data processing unit. Stud 10 is rigidly connected to disc 5 and, when it is moved up or down, the pressure on the sensing element made of OF increases or decreases. If there is a displacement of the layers of the roof of the working, stud 10 moves upwards as it is connected, through hole 11, to cable 13. Since when moving the layers, the spring retainer 14 , located in borehole 15, comes into motion, the pressure on the sensing element increases. For the correct installation of FOS in the borehole, a guide system 12 is used, it is similar in design to the guide system of the reference station. The principle of FOS operation is quite simple and is based on the method of controlling additional losses in the $\mathrm{OF}$ and changing the properties of light. The greater the displacement of rocks, the greater the mechanical impact on the sensing element, and, respectively, the greater the changes in the parameters of the light wave.

5. 4. Results of designing a hardware-software system for a quasi-distributed system

To control the parameters of FOS, a laboratory version of a four-channel hardware-software system has been developed. Laboratory FAIS includes a coherent radiation source with a wavelength of $650 \mathrm{~nm}$ and a power of $30 \mathrm{~mW}$ : the general view was shown above in Fig. 6 . The hardware-software system can have different settings for effective work with FOS. Fig. 11 shows a window of the hardware-software system, which has a measuring scale and settings buttons.
Settings may vary depending on the conditions of the mining enterprise and the need to set an alarm threshold in case of a threat of collapse or a warning of a sharp change in mountain pressure at the measuring point. Initially, the program makes it possible to calibrate the connected FOS and its television matrix. Since the distance from the data processing unit to the FOS can vary from hundreds of meters to tens of kilometers, the incoming light spot would have a different size and area. The stage of adjusting the sensitivity of the camera and adjusting the image of the spot to a certain size is carried out. To this end, click the "camera calibration" tab and make the adjustment, then save the set sensitivity parameters, and close the window. Also, when setting up the camera, one can determine whether the radiation source is coherent. This is a very important circumstance since the failure of the laser could lead to disruptions in the work of the entire FAIS in general. Regulation of the laser supply voltage makes it possible to adjust its power, respectively, select its power according to the distance from the unit to the measuring point. Reducing or exceeding the supply voltage leads to the degradation of the laser and its failure. In the case of laser failure, breakage of the OF in the sensor or guide system, the alarm is activated, which makes it possible to react in time to the emergency state of the FAIS.

The second stage of adjustment involves checking the program and its adaptation to the environmental conditions of the mining enterprise, as well as training the threshold of alarm. The need for an alarm system was put forward as one of the requirements on the part of the future customer, the coal department at ArcelorMittal Temirtau JSC (Kazakhstan). The FAIS should not only measure the displacement parameters of layers when the mountain pressure changes but also ensure the safety of workers. The alarm system operates under three modes. "Normal" mode glows green. When the displacement parameters change or the layers move, a warning signal is triggered in the form of a yellow pointer. When there is a threat of danger of collapse with a sharp displacement of the formation, the red sign "Alarm" lights up. Warning and alarms are given at different frequency sound signals to attract the operator's attention.

To configure, click the "Run in debug mode" tab, and the window appears that is shown in Fig. 12. Debug mode shows plots with numerical values of changes in values and changes in parameters during a certain period "Number of events" for averaging. Calibration at the initial stage involves establishing a zero value. The program window is also divided into two parts. On the left is a black window where the image from the camera is displayed in real time. On the right, the result is displayed in the form of a picture of changing pixels and moving them from black to white. At startup, all windows are black; the plots are straight lines.

An important point in the creation of the project is the design of visualization subsystems, the stage of determining the variables of "tags", to determine the numerical value of the input and output points of information. At the same time, in the settings, changes are made online by the user. If necessary, the user can make changes to the parameters of triggering the tag, Alarm, trend without rebooting the system, only by clicking the "Apply" button. All information about the triggering and measurements is stored on the hard disk of the computer, and the report is generated automatically. If necessary, information can be retrieved from memory for further analysis. 


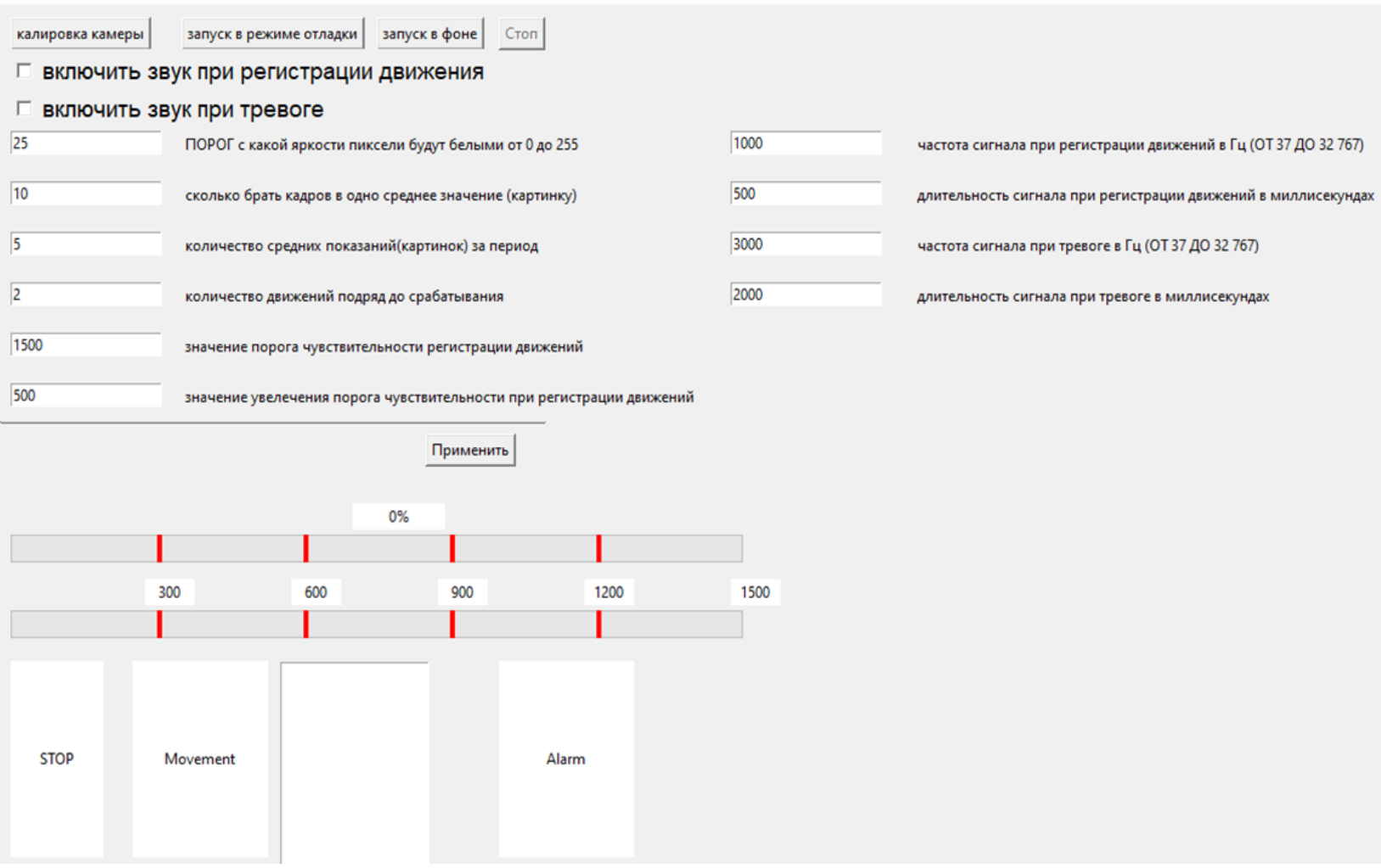

Fig. 11. Window of FAIS hardware-software system
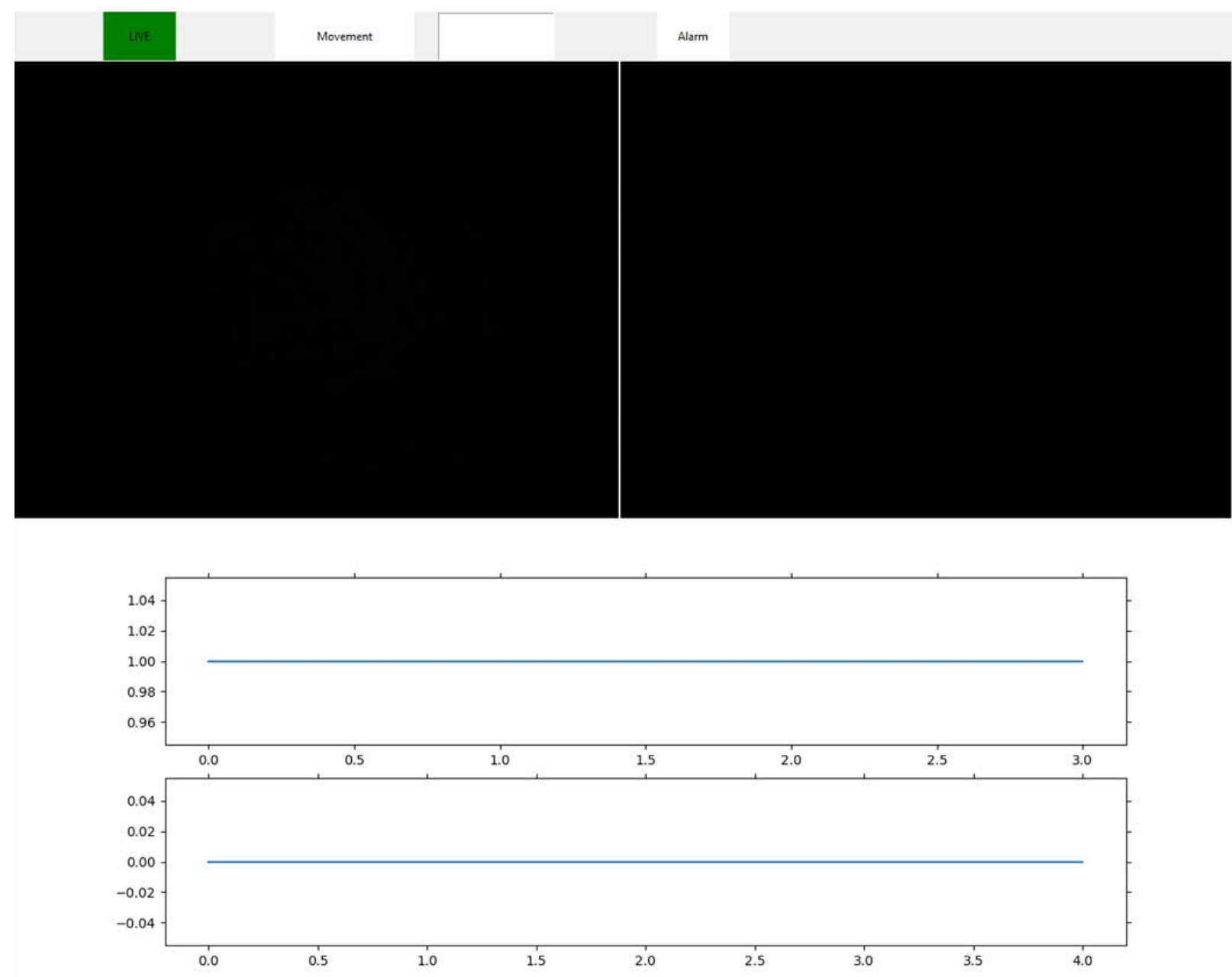

Fig. 12. Run in Debug Mode window 
The "Alarm" function is necessary for a warning in the form of a separate message, which can be transmitted to a mobile phone to a group of users. To this end, the hardware-software system is equipped with a $4 \mathrm{G}$ modem. Alarm is transmitted to the operator in the form of a message indicating the time of triggering the warning or alarm. Visually, the operator sees information on the monitor screen, which allows him to make a decision and perform actions to eliminate an abnormal situation in the technological process. In parallel, the operator would receive a warning sound signal if he is distracted from the screen and does not see changes. The warning signal is disabled by the operator using a button. After starting the program in the background, separate white dots would appear on the screen on the right - the noise of the measuring channel. In this case, the report would be shifted by the amount of this noise. Within a minute, the program itself conducts automatic calibration and shifts the "Zero" by the amount of noise. Fig. 13 shows the window of the program "Run in debug mode", on the window on the right - white pixels have already appeared and there are numerical values of the measured value but this is only the noise caused by the passage of a light wave along the core of a single-mode OF.

If the OF placed inside the body of the FOS or the guiding communication system has heated up or cooled, the amount of noise would increase. Without dynamic noise suppression, the operation of the FAIS would be disrupted, and it will give false data while the situation at the facility would not change. The system also evaluates the fluctuations of the radiation source and does not respond to these changes in the case of its temporary failure. A warning signal can also be given to check the operation of the laser.

The nature of noise and the nature of the mechanical impact on $\mathrm{OF}$ are different, the change in the picture of pixels in speed, frequency, and other parameters is different. Therefore, the displacement of the rock can be clearly identified without error. Fig. 14 shows a pattern of the change in pixels when FOS is impacted during laboratory tests illustrated in Fig. 6.

When tightening the tension couplings, there was a displacement of the stud, which acted on the OF through the movable disc. At the same time, the fiber was pinched and a micro bending was formed. The OF must be placed on an elastic polyurethane damper to exclude damage to the $\mathrm{OF}$ and ensure the return to the original position of the FOS. As one can see on the screen on the left, the camera captures the change in the shape of the spot and the activation of noise at the interface of the media. The screen on the left shows that the number of white pixels has increased, the value on the plot has changed, and there is an increase. The spot changes its shape while the noise increases. This can be seen in the individual bursts of white dots at the inner and outer edge of the spot. Since there are no separate bursts of load on the OF and there are no dynamics of changes in the magnitude of the impact, the load increases smoothly and slowly, the upper plot is not active.
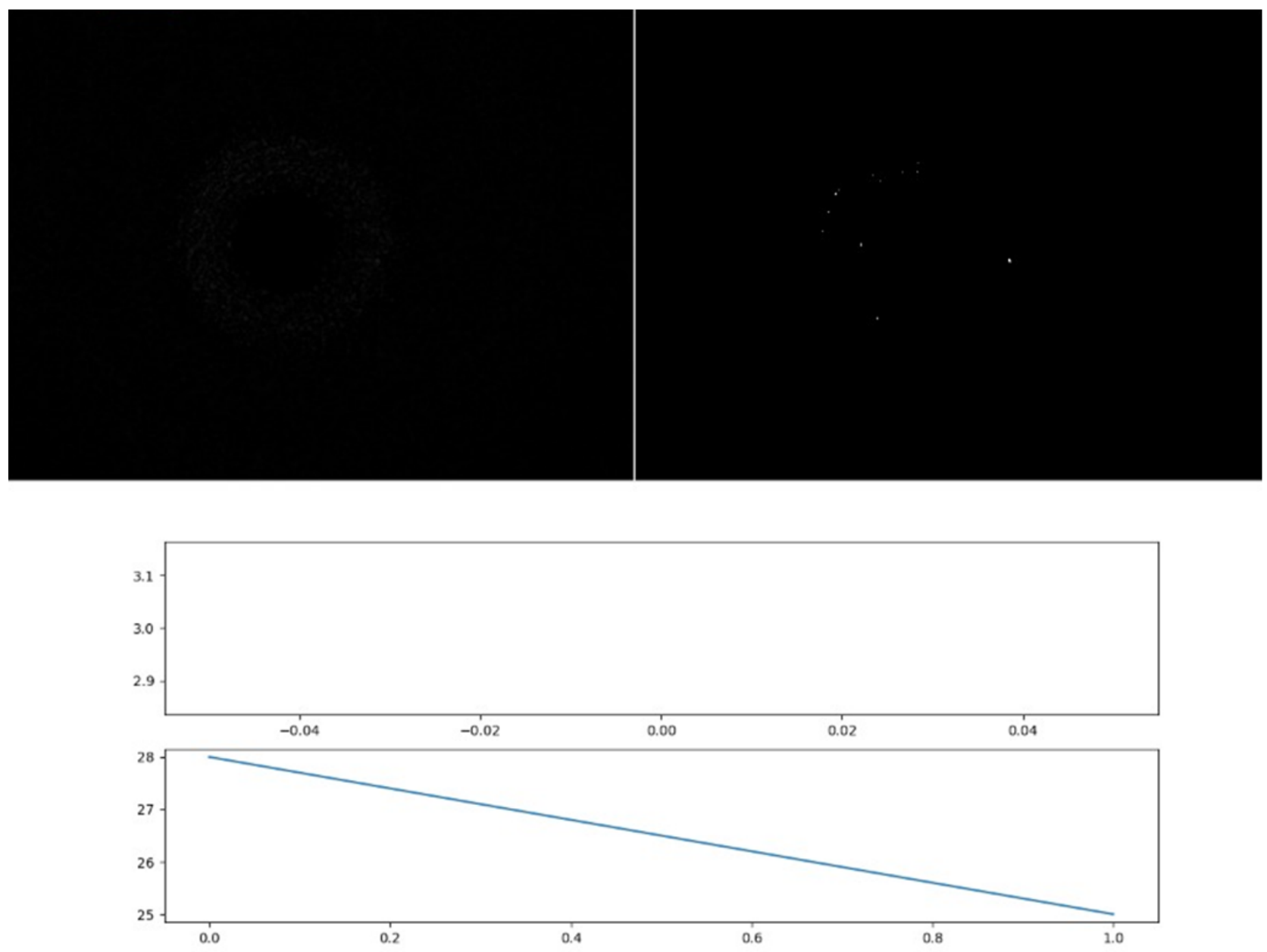

Fig. 13. Run in Debug Mode window 

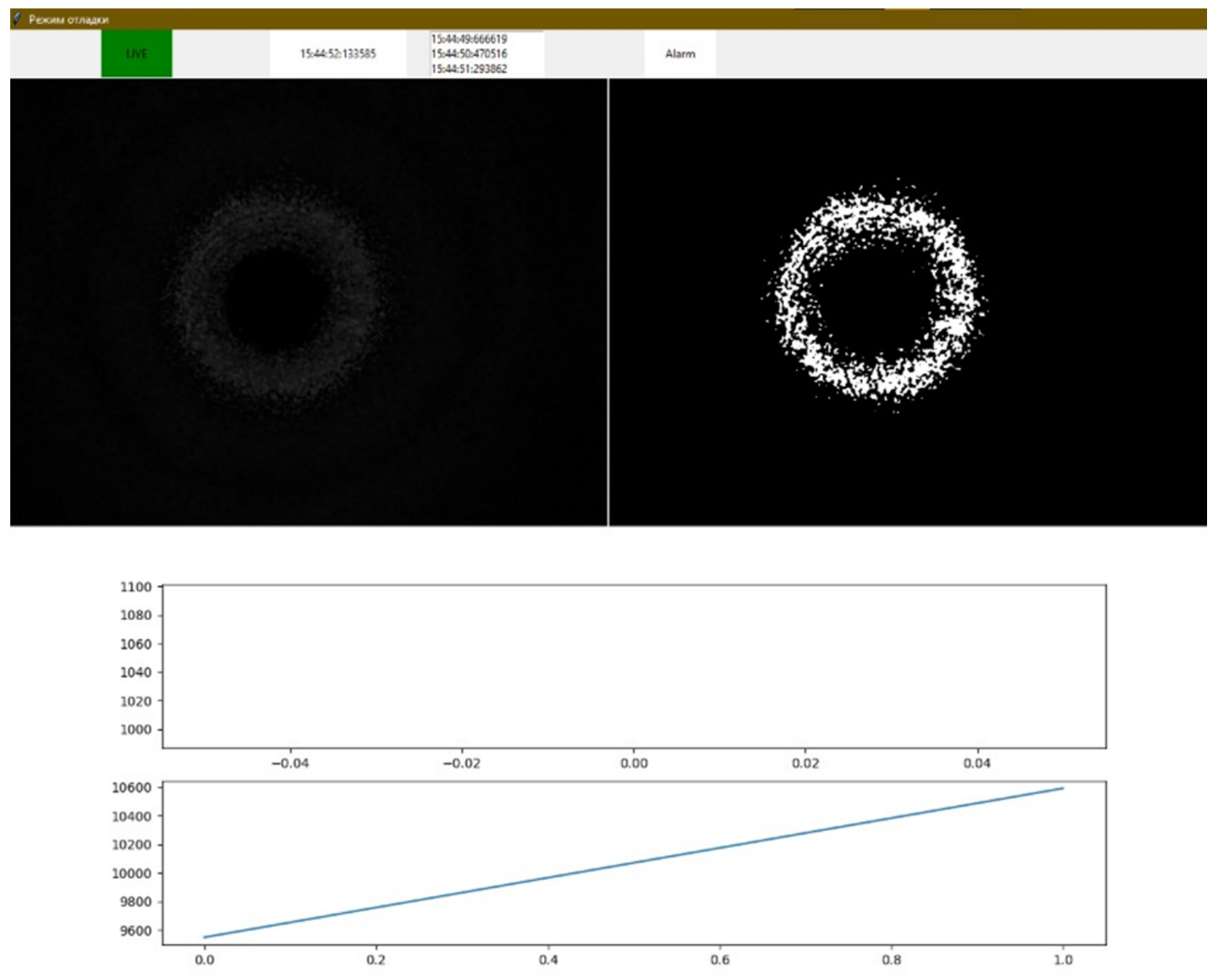

Fig. 14. Run in Debug Mode window when an initial offset occurs

If one acts on the OF several times within one second or for another set period, then the data of the impact would be reflected on the upper plot. Fig. 15 shows that the load on the FOS increases and the displacement increases in its magnitude. It can be seen that the white spot has increased in size but the noise is also growing, blurring its boundaries. The same thing happens on the left screen, where a video image of the spot is broadcast in real time.

Since there are no sharp fluctuations and changes in the frequency of exposure, in the period determined by the settings, the alarm does not work. About $25 \%$ of the total possible range of movement of the stud has been passed. At the end, a limiter is installed to limit the movement of the stud, since it is possible to achieve the tensile strength of the OF at micro bending. The OF bending is limited as the critical value would lead to irreversible damage and failure of FOS. Also, the transition of the critical value of the angle of micro bending would lead to the formation of microcracks in the body of the OF and its subsequent fatigue destruction. FOS can be adjusted to measure displacements from $1 \mathrm{~mm}$ to 1 meter. In this case, one FOS can be equipped with two or three OFs to increase the measurement range and control several levels of rock.
If necessary, it is possible to control several layers located in the roof of the working, then the FOS may contain two or three sensing elements that are connected to different channels.

Fig. 16 shows that the spot has grown to almost maximum size and the displacement is approximately $90 \%$ of the total measurement range. Noises also increased while the shape of the spot became blurred. The numerical values of the measured value also increased. The plot of the magnitude went down as the moment of the beginning of the reverse stroke of the stud of reducing the load is captured. In the program window, one can see how the load was changed during the time when the clutch was stretched. The load increased smoothly and slowly for 6 minutes.

If necessary, the program can be interrupted by clicking the "Stop" button, and reconfigure the parameters, and then click the "Apply" button. After that, the program is ready to work again. The program has several settings, the main ones are displayed on the operator's console. One can set the brightness threshold of white pixels, which helps with the initial setting on any object since the distances from the FOS to the data processing unit may vary. There are also several settings related to the averaging of parameters, to exclude the influence of noise on the measurement process, as well as alarm thresholds. 

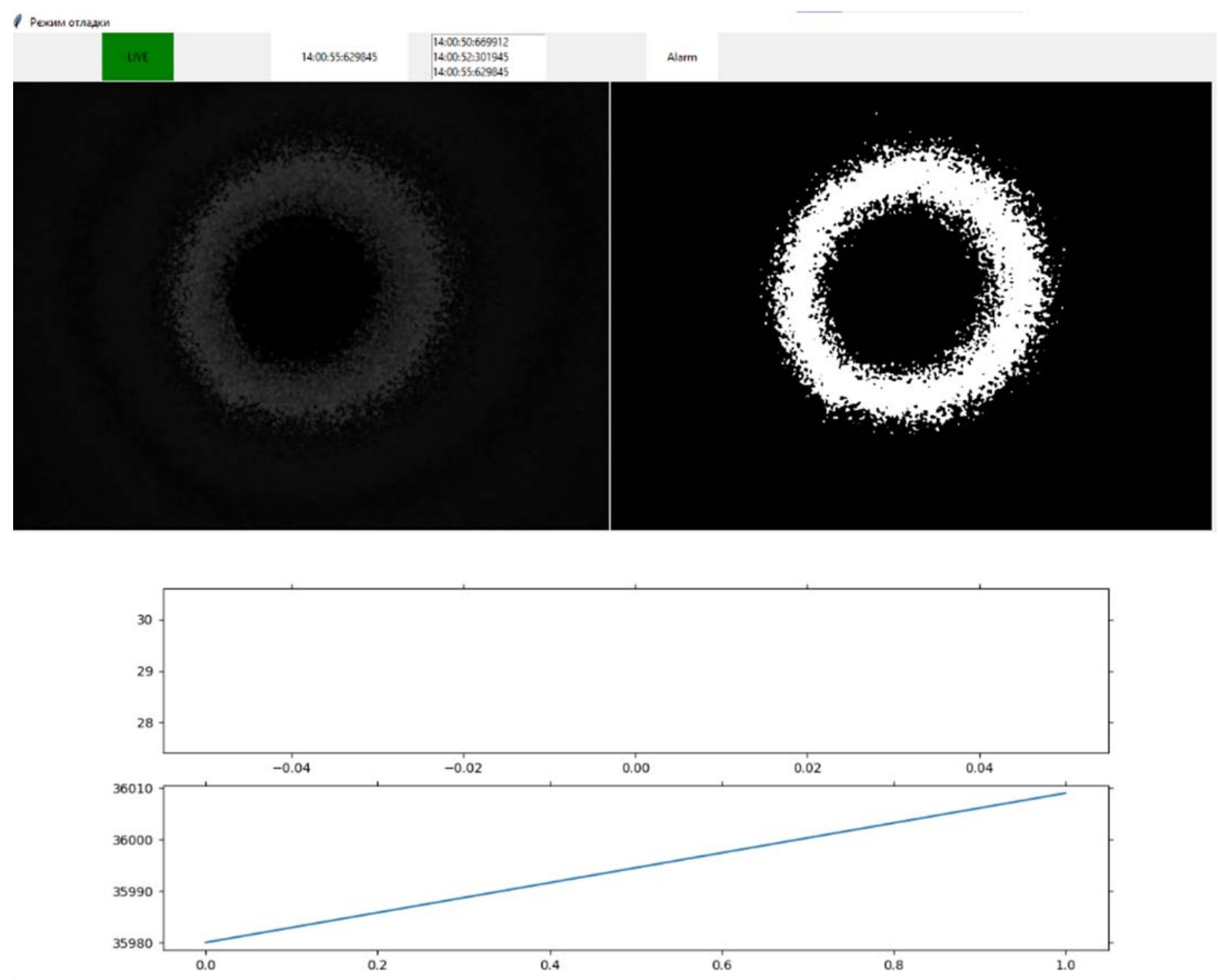

Fig. 15. Run in Debug Mode window when offset occurs, intermediate step

When squeezing the fiber, the parameters of the light spot falling on the surface of the television matrix installed at the output of the OF change. The principle of FAIS operation is based on the control of these parameters, which is fundamentally different from the known methods built on the basis of an interferometer, reflectometer, Bragg gratings. Even the departure of the light spot from the center of the camera does not cause problems in the work of the FAIS. In terms of brightness, a different variation of spots is possible, depending on the distance. The shape of the light spot, depending on the distance, is shown in Fig. 17.

If the light spot goes beyond the boundaries of the concentric circle, the fifth from the center, or, vice versa, becomes smaller than the first central circle, the normal FAIS operation becomes impossible.

Since the experiments used a semiconductor laser with a power of $30 \mathrm{~mW}$ with a wavelength of $650 \mathrm{~nm}$, its power is enough for a distance of $5-6 \mathrm{~km}$. If the FOS is installed at a relatively close distance in the range from hundreds of meters to one kilometer, the light spot would be brighter (Fig. 17, $a$ ). Within 1-3 kilometers, the spot does not greatly decrease in size (Fig. 17, b). At a distance of about $5 \mathrm{~km}$, the spot decreases quite noticeably (Fig. 17, c). At a distance of $7 \mathrm{~km}$, it is greatly reduced, which can adversely affect FAIS operation (Fig. 17, $d$ ). The laser used has several power levels from 10 to $50 \mathrm{~mW}$ and, if necessary, one can control the pumping of its power.
Displacement was simulated by tightening tension couplings. The OF demonstrates micro bending while the refractive index between the shell and the core changes, as a result of which the properties of the light wave at the outlet of the optical fiber change. Changes in the properties of light relate to the intensity and phase of propagation, which is reflected in the change in the shape of the light spot. In the process of micro bending an OF, there is a known effect of photoelasticity; and, respectively, the higher the pressure on the $\mathrm{OF}$, the greater the additional losses of propagating radiation. The effect of photoelasticity is accompanied by the withdrawal of light mode beyond the shell and the loss of part of the optical power. All changes are recorded by the hardware-software system and displayed on the screen.

The program has several windows for its configuration and operation. In the process of work, numerical values of the load are displayed on the screen, the value of which is used to calculate the displacement. Signal signs of green, yellow, and red colors are also displayed, which are necessary to warn about the danger or, vice versa, about the normal operation of the system. With a sharp fluctuation in pressure and an increase in the displacement parameter, a warning signal is triggered, and a yellow indicator is turned on, indicating that the roof rocks have come into motion due to an increase in mountain pressure. 

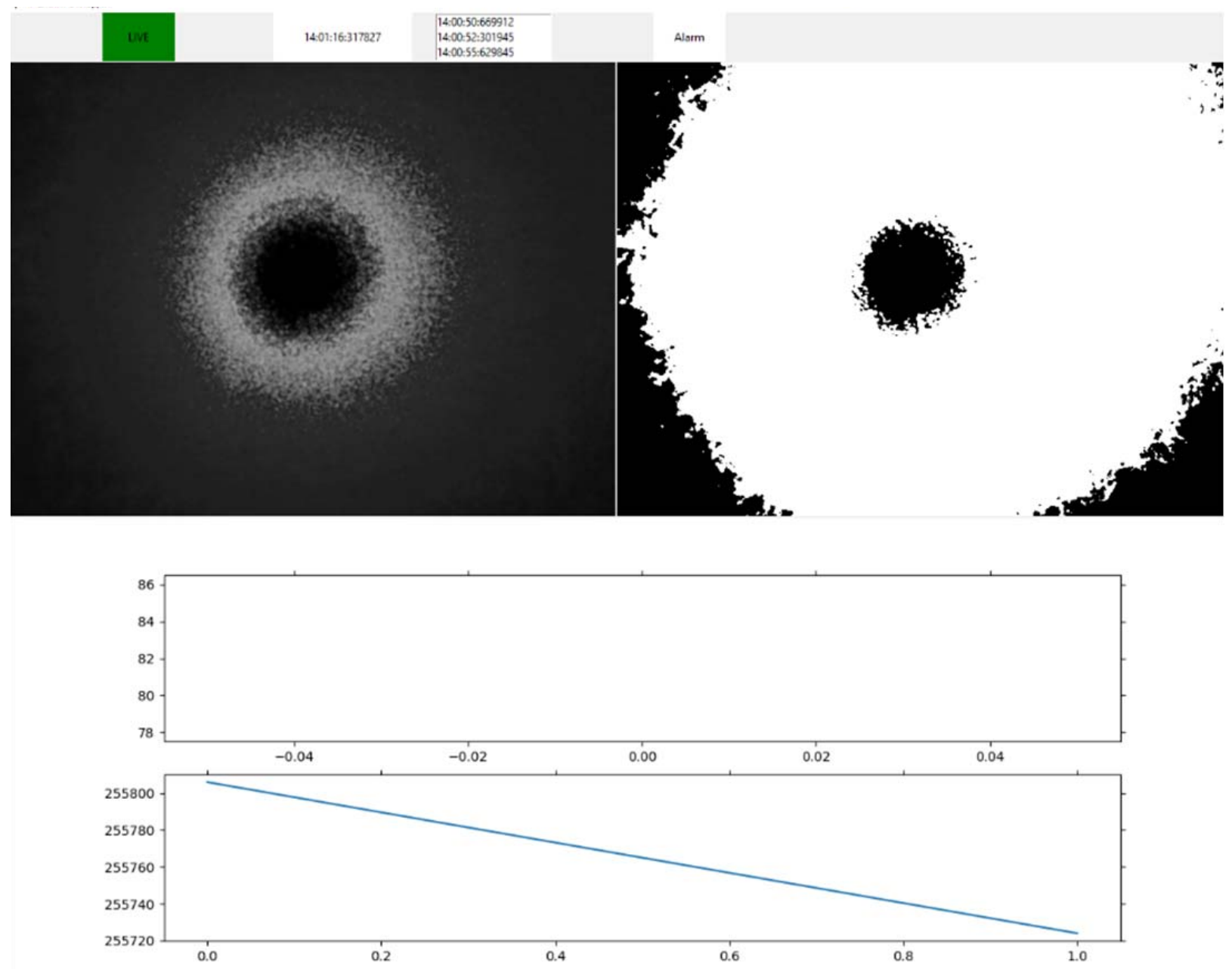

Fig. 16. Run in Debug Mode window when offset occurs, final step

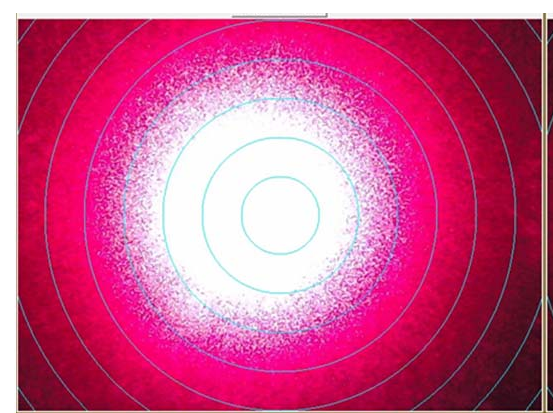

$a$

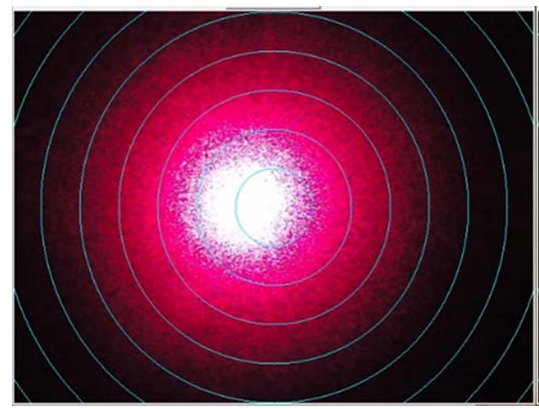

c

Fig. 17. The shape and size of the light spot depending on the length of the measuring channel: $a-$ measuring channel up to $1 \mathrm{~km} ; b-$ measuring channel $1-3 \mathrm{~km} ; c-$ measuring channel $3-5 \mathrm{~km} ; d-$ measuring channel $5-7 \mathrm{~km}$

\section{Discussion of results of studying the development of prototypes of a low- pressure steam electric heater}

All results have been obtained empirically during full-scale experiments. Constant changes in the phase of propagation of the light wave lead to interference, so it is important to take into consideration not only the influence of temperature but also the coherence parameters of the radiation source ((1) to (3)). These expressions explain that the laser power supply must have high stability with a low level of ripples. The temperature correction performed at the hardware-software level makes it possible to reduce the impact of interference and delays of pulse repetition in self-oscillation mode. The dependence of the refractive index of the core on temperature and deformations (3) has been proven. The change in the phase of propagation of the light wave in OF occurs when the temperature changes within $1{ }^{\circ} \mathrm{C}$; this could lead to the system freeze and false triggering while there was no mechanical effect on the sensor. The delay in the accumulation 
of pulses depends on the length of the measuring channel, which leads to errors in measurements when the temperature changes.

The fiber-optic sensor of deformation and displacement of rock massif layers has significant advantages in comparison with standard reference stations: FOS has the ability to return to the initial position, is designed for remote measurement, carries out measurements in real time (Fig. 5). Our results of the dependence of optical losses on the applied force showed high linearity of FOS (Fig. 6).

The quasi-distributed fiber-optic measurement system includes a FOS circuit, a light source, and a data acquisition and processing device (Fig. 9). To increase the distance and the number of simultaneously working FOSs, it is necessary to increase the power of the laser or use several lasers, which makes it possible to increase the length of the measuring channel. Lasers are combined using an optical splitter, but it is necessary to select lasers with similar characteristics. During the experiment, the selection of lasers with a capacity of $20 \mathrm{~mW}$ was carried out. This is enough for a measuring channel with a length of about $10 \mathrm{~km}$. With an increase in the distance, losses in the OF would grow, so one needs to increase the laser power or the length of the light wavelength.

The program has a dynamic range of contrast, brightness, exposure, white balance, and more, which makes it possible to make adjustments if necessary. Accordingly, one can increase or decrease the brightness and size of the light spot in the "Camera Setup" tab (Fig. 17). Unlike existing analogs of FAIS, which use the physical principles of optical interferometry, reflectometry, Bragg grating effects, the proposed method is less susceptible to interference arising in a single-mode OF. The hardware-software system works on a completely different principle of construction and analyzes changes in the light spot at the output of the optical fiber and gives numerical values depending on the number of white pixels (Fig. 14-16). This completely avoids the problems associated with the influence of increasing noise and changing the phase of signal propagation when the external temperature changes. It can also be noted that a serious problem is the incoherence of the radiation source as this leads to an increase in the noise level; existing algorithms and the hardware-software part do not cope with the task of suppressing interference. During the experiment, a laser was selected that creates the least noise of the light wave at the exit from the OF.

The study results are applicable to building a measuring system operating with a wavelength of $650 \mathrm{~nm}$, for a distance of up to $20 \mathrm{~km}$, at a radiation power of $30 \mathrm{~mW}$. No studies into the system with a light wavelength of 850 and $950 \mathrm{~nm}$ have been conducted.

The first thing that needs to be done in the future to improve the laboratory prototype of FAIS and FOS and conduct full-scale tests in the mine is to finalize the software in the field of machine learning. That would increase the level of adaptability of the system to various conditions, as well as reduce the level of probability of false triggering. The second stage would be the use of a neural network to process the measurement results and increase the noise immunity of the system. The third stage could be the transition of the wavelength of the radiation source from 650 to $850 \mathrm{~nm}$ to increase the distance from the data processing unit to the FOS.

\section{Conclusions}

1. Investigating the process of formation of additional losses at micro bending, taking into consideration the effect of photoelasticity, it can be noted that the mechanical effect on OF leads to a change in the properties of light. Changes in the properties of the light wave propagating through the core of the optical fiber occur during the bending of the $\mathrm{OF}$ and are associated with the effect of photoelasticity, while there is a slight change in the refractive index $n$ between the core and the shell of the OF. It was found that an increase in the length of the light wave leads to a decrease in the additional losses in the OF and, when micro bending occurs, the opposite effect is noted. As the wavelength increases, the losses increase. The results of the theoretical studies of additional losses, taking into consideration the effect of photoelasticity, could be used in the design of FAIS, which would have no foreign analogs and could function on a new principle. The cost of one point of measurement in a quasi-distributed system based on the method of controlling additional losses would be lower.

2. The designed FOS has a structure similar to a mechanical reference station, which would make its production less costly. Our experimental studies have shown that FOS can be configured to measure displacements from $1 \mathrm{~mm}$ to 1 meter, which is enough for its use in any mine workings of coal mines. The study results have shown that FOS is able to control the displacement of rocks by 30 centimeters more than the reference station. In this case, one FOS can be equipped with two or three OFs to increase the measurement range and control several levels of rock. If necessary, it is possible to control several layers located in the roof of the working, then the FOS may contain two or three sensing elements that are connected to different channels. The fiber-optic sensor has fairly high linearity of characteristics.

3 . The research results are the designed measuring scheme of the quasi-distributed measurement system and the sensor structure. The quasi-distributed measurement system is based on a measuring circuit in which each FOS is connected to a separate television matrix to control the change in the parameters of the light spot. Since the FOS is connected only by one OF, a stepped profile of the light spot is formed, there is no interference light spot. The proposed system differs from the interferometer in that it analyzes changes in the intensity of the light spot and converts black and white into pixels. At the same time, it contains a significant amount of noise, which adversely affects FAIS operation. The greater the displacement of rocks, the greater the mechanical impact on the sensing element. Accordingly, the larger the changes in the parameters of the light wave and the transition of more pixels from black to white.

4. The study result is a designed prototype of the hardware-software system for a quasi-distributed system to measure the deformation and displacement of rock massif layers. The hardware-software system is multi-channel and makes it possible to warn the operator in the event of displacement of rock layers by triggering the alarm and sending a message to various means of communication. At all stages of setting up the hardware-software system, the features and conditions of a particular mining enterprise are taken into consideration. The program has several windows for work, which display numerical values of the load, the value of which is used to calculate a displacement. 


\section{Acknowledgments}

The study reported in the paper was conducted at the material and technical base of the Kazakh Agrotechnical University named after S. Seifullin, as well as Karaganda
Technical University, within the IRN grant No AP09562222 "Information-measuring system of a new generation based on fiber-optic sensors" (contract 254/12-2 dd. 15.07.21), as well as part of the dissertation thesis for the $\mathrm{PhD}$ degree by B. Aubakirova.

\section{References}

1. Liu, X., Wang, C., Liu, T., Wei, Y., Lv, J. (2009). Fiber Grating Water pressure sensor and system for mine. ACTA Photonica Sinica, 38, 112-114. Available at: https://www.researchgate.net/publication/292872640_Fiber_grating_water_pressure_sensor_and_ system_for_mine

2. Kumar, A., Kumar, D., Singh, U. K., Gupta, P. S., Shankar, G. (2011). Optimizing fibre optics for coal mine automation. International Journal of Control and Automation, 4 (3), 19-30. Available at: http://article.nadiapub.com/IJCA/vol4_no3/2.pdf

3. Naruse, H., Uehara, H., Deguchi, T., Fujihashi, K., Onishi, M., Espinoza, R. et. al. (2007). Application of a distributed fibre optic strain sensing system to monitoring changes in the state of an underground mine. Measurement Science and Technology, 18 (10), 3202-3210. doi: http://doi.org/10.1088/0957-0233/18/10/s23

4. Chotchaev, Kh. O. (2016). Control of the mountainous area stress-strained state by the sound ranging and geophysical methods. Geologiya i geofizika yuga Rossii, 3, 129-140. Available at: https://www.elibrary.ru/item.asp?id=27170260

5. Buimistryuk, G. Ya. (2011). Printsipy postroeniya intellektualnykh volokonno-opticheskikh datchikov. Foton-Ekspress, 6 (43), 38-39.

6. Buimistryuk, G. (2013). Volokonno-opticheskie datchiki dlya ekstremalnykh uslovii. Control engineering Rossiya, 3 (45), 34-40. Available at: https://controleng.ru/wp-content/uploads/ce_46_p34_volokonno-opticheskie_datchik_dlya_ ekstremalnykh_uslovii.pdf

7. Kim, S., Park, Y., Park, S., Cho, K., Cho, J.-R. (2015). A Sensor-Type PC Strand with an Embedded FBG Sensor for Monitoring Prestress Forces. Sensors, 15 (1), 1060-1070. doi: http://doi.org/10.3390/s150101060

8. Liu, T., Wei, Y., Guangdong Song, Li, Y., Jinyu Wang, Yanong Ning, Yicheng Lu. (2013). Advances of optical fiber sensors for coal mine safety monitoring applications. 2013 International Conference on Microwave and Photonics (ICMAP), 102-111. doi: http:// doi.org/10.1109/icmap.2013.6733455

9. Zhao, Y., Zhang, N., Si, G. (2016). A Fiber Bragg Grating-Based Monitoring System for Roof Safety Control in Underground Coal Mining. Sensors, 16 (10), 1759. doi: http://doi.org/10.3390/s16101759

10. Volchikhin, V. I., Murashkina, T. I. (2001). Problemy sozdaniya volokonno-opticheskikh datchikov. Datchiki i sistemy. Izmereniya, kontrol, avtomatizatsiya, 7, 54-58. Available at: http://naukarus.com/problemy-sozdaniya-volokonno-opticheskih-datchikov

11. Liu, J., Chai, J., Wei, S., Li, Y., Zhu, L., Qiu, B. (2008). Theoretical and experimental study on fiber Bragg grating sensing of rock strata settlement deformation. Journal of Coal Science and Engineering (China), 14 (3), 394-398. doi: http://doi.org/10.1007/ s12404-008-0087-0

12. Kamenev, O. T., Kulchin, Yu. N., Petrov, Yu. S., Khizhnyak, R. V. (2014). Primenenie volokonno-opticheskogo interferometra MakhaTsendera dlya sozdaniya dlinnobazovykh deformometrov. Pisma v ZHTF, 40 (3), 49-56. Available at: http://journals.ioffe.ru/ articles/viewPDF/27305

13. Kulchin, Yu. N., Kamenev, O. T., Petrov, Yu. S., Kolchinskii, V. A. (2016). Volokonno-opticheskie interferometricheskie priemniki slabykh seismosignalov. Vestnik DVO RAN, 4, 56-59.

14. Shumkova, D. B., Levchenko, A. E. (2011). Spetsialnye volokonnye svetovody. Perm: Izd-vo Perm. nats. issled. politekhn.un-ta, 178. Available at: https://pstu.ru/files/file/FPMM/of/shumkova_specialnye_volokonnye_svetovody.pdf

15. Buimistryuk, G. Ya. (2004). Informatsionno - izmeritelnaya tekhnika i tekhnologiya na osnove volokonno-opticheskikh datchikov i sistem. Saint Petersburg: IVA, GROTS Minatoma, 198. Available at: https://www.twirpx.com/file/102146/

16. Osório, J. H., Chesini, G., Serrão, V. A., Franco, M. A. R., Cordeiro, C. M. B. (2017). Simplifying the design of microstructured optical fibre pressure sensors. Scientific Reports, 7 (1). doi: http://doi.org/10.1038/s41598-017-03206-w

17. Yurchenko, A. V., Mekhtiyev, A. D., Bulatbayev, F. N., Neshina, Y. G., Alkina, A. D. (2018). The Model of a Fiber-Optic Sensor for Monitoring Mechanical Stresses in Mine Workings. Russian Journal of Nondestructive Testing, 54 (7), 528-533. doi: http:// doi.org/10.1134/s1061830918070094

18. Mekhtiev, A. D., Yurchenko, A. V., Ozhigin, S. G., Neshina, E. G., Al'kina, A. D. (2021). Quasi-Distributed Fiber-Optic Monitoring System for Overlying Rock Mass Pressure on Roofs of Underground Excavations. Fyzyko-Tekhnycheskye Problemi Razrabotky Poleznikh Yskopaemikh, 2, 192-198. doi: http://doi.org/10.15372/ftprpi20210219

19. Mekhtiyev, A. D., Yurchenko, A. V., Neshina, E. G., Alkina, A. D. (2020). Using G-652 Optical Fiber to Control Mountain Massifes of Coal Mines. Bulletin of the South Ural State University. Ser. Computer Technologies, Automatic Control \& Radioelectronics, 20 (1), 144-153. doi: http://doi.org/10.14529/ctcr200114 